\title{
Tabaré Etcheverry, un breve cantar
}

\author{
Tabaré Etcheverry, um breve cantar \\ Tabaré Etcheverry, a short song \\ Juan Carlos Albarado \\ Universidad de la República, Montevideo, Uruguay
}

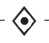

Resumen: Parece entremezclarse, como lo anuncia en uno de sus textos, una cuestión de suerte en la popularidad, o no, de Tabaré ETCHEVERRY. Sobres fines de la década del 70, en el Uruguay, Etcheverry puede pensarse como una especie de bisagra en la cual se amalgaman dos períodos decisivos en la música uruguaya. Comienza a operarse un cambio significativo en la concepción de la canción que unirá a figuras tan disímiles como Los Olimareños, Leo Maslíah, Carlos Cresci e incluso un grupo que inició apuntando a un público infantil, Canciones para no dormir la siesta. El presente trabajo, fruto de una investigación en curso, pretende dar cuenta de aspectos biográficos de José Francisco Etcheverry Tort (1945-1978) y su vinculación con la canción en el Uruguay, su concepción estética, así como de cuestiones políticas que, entre otras cosas, fraguaron una cierta leyenda negra sobre este cantautor.

Palabras clave: Canción en el Uruguay; Dictadura; Canción protesta

Resumo: Parece se misturar, como ele anuncia em um de seus textos, uma questão de sorte na popularidade, ou não, do cantor e compositor Tabaré ETCHEVERRY. O final dos anos 70, no Uruguai, atua como uma espécie de dobradiça em que dois períodos decisivos são amalgamados em nossa música. Começa a sofrer uma mudança significativa na concepção da música que, agora, vai unir figuras tão diferentes como: Los Olimareños, Leo Maslíah, Carlos Cresci e até mesmo um grupo que começou a atingir a audiência das crianças, Canções para não cochilar. O presente trabalho, fruto de uma pesquisa em curso, tenta dar conta dos aspectos biográficos de José Francisco Etcheverry Tort (1945-1978) e da sua conexão com a música no Uruguai, sua concepção estética, bem como questões políticas que, entre outras coisas, gerou uma certa lenda negra sobre esse cantor e compositor.

Palavras-chave: Canção no Uruguai; Ditadura; Canção de protesto

\begin{abstract}
It seems to intermingle, as he announces in one of his texts, a matter of luck in the popularity, or not, of the singer-songwriter Tabare ETCHEVERRY. The end of the 70s, in Uruguay, acts as a kind of hinge in which two decisive periods are amalgamated in our music. Begins to undergo a significant change in the conception of the song that, now, will unite such dissimilar figures as: Los Olimareños, Leo Maslíah, Carlos Cresci and even, a group that began targeting the children's audience, Canciones para no dormir la siesta. The present work, fruit of an investigation in course, tries to give account of biographical aspects of José Francisco Etcheverry Tort (1945-1978) and its connection with the song in Uruguay, its aesthetic conception, as well as of political questions that, among others things, forged a certain black legend about this singer-songwriter.
\end{abstract}

Keywords: Song in Uruguay; Dictatorship; Song protest 


\section{Introducción}

En el año 2003, el periodista Guillermo Pellegrino escribió un artículo de tres páginas sobre Tabaré Etcheverry para el suplemento Cultural del diario El País, titulado "El cantor olvidado". Este es el trabajo más extenso que he hallado hasta la fecha. En él aborda algunas cuestiones relativas a su biografía, sus comienzos como cantor, y las vicisitudes que sufrió el joven acostumbrado a una ciudad pequeña y de la frontera norte de Uruguay, como Melo, donde había vivido y desde la que se trasladó a la capital, por un lado, y de sus peripecias como cantor de protesta en épocas de la dictadura (1973-1984), por el otro.

Ningún libro existe sobre Etcheverry en particular, todas las referencias halladas hasta el momento pertenecen a obras o estudios generales sobre el denominado Canto Popular o la poesía de los años sesenta y setenta. Todos los autores, a excepción de la breve semblanza que realiza Tabaré Arapí en su libro Las voces del silencio (2006), recogen y sintetizan el material elaborado por Pellegrino, vr. Gr.: Duarte (2010); Bravo (2012); Nazabay (2013).

Es posible avanzar desde el trabajo de Pellegrino no solo porque, como expresa Dosse (cf. 2007), cada generación renueva las biografías sino porque siempre se puede contar con la aparición de un nuevo material, una perspectiva teórica diferente, o incluso nuevas pistas que pueden conducir no solo a la reinterpretación de una vida sino también de una época.

Uno de los hallazgos más notables fue un cuaderno grueso, de tapas verdes y hojas amarillentas que conserva su viuda, Ivonne Abella, que me fuera gentilmente proporcionado en el año 2010, y al que logré transcribir sin muchas dificultades puesto que su letra cursiva es clara y las disortografías no pasan de tildes y la ausencia de algunas haches, pese a lo enunciado por Pellegrino: "escribió cuentos - que hoy duermen en un cuadernoplagados de faltas de ortografía. ¿Sería esta otra 'licencia rebelde'?" (2003, p. 8). El cuaderno, aún inédito, es en realidad una especie de diario, escrito entre 1976 y 1977. En él registra narraciones, anécdotas y recuerdos siempre bajo un perfil crítico acerca de los múltiples temas que toca. Según su viuda no es un cuaderno en el que pasara en limpio textos, sino que simplemente escribía $\mathrm{y}$, sin embargo, hay escasas correcciones, cada tanto una palabra o una frase tachada y en una oportunidad todo un párrafo de cinco o seis renglones, pero no más que eso.

Ese cuaderno-libro comienza con reflexiones acerca de la conquista española hasta la época de Artigas, con consideraciones especialmente duras hacia algunos caudillos: "Ya lo negarán [a Artigas], Rivera y Lavalleja. Se encargarán de crear sus «historias negras» que considero conveniente ni nombrarlas, porque el asco se nos viene boca arriba y no quisiéramos en palabras vomitarlo." ("Presente y futuro" en Cuaderno de Tabaré, en adelante CdT). Luego, se relata el viaje de un niño en un tren a la capital y, a partir de ahí, el Seminario, su alejamiento del mismo, la búsqueda en Montevideo de un espacio y, hacia el final, unos cuentos que podrían clasificarse como de realismo social, llegando a citar la novela La madre, del escritor ruso Mákxim Gorki. El viaje culmina el día 13 de diciembre de 1977. Resulta evidente que Tabaré pensaba en él como un libro, incluso se hace alguna referencia a esto: "Que se vayan a la misma mierda, ya me tienen po-dri-do. Entendés. Po-dri-do. Lo único que falta es que al entrar al baño mi vieja me limpie la cola (Dijo culo, pensé que sería mejor no utilizar el término en el libro, por razones de pudor)" ("Regreso" en CdT). Se manifiesta, de esta forma, el conocimiento que tenía el autor acerca del carácter ambiguo de este material que por un lado oficia como diario, pero por otro podría servir (y este trabajo es una prueba) como parte del archivo acerca de él.

\section{Orígenes: La Pedrera y la Posta del Chuy}

Viejas casonas de piedra Posta del arroyo Chuy ya tus cadenas no existen pero reviven en mí...

Una lágrima brota en la leyenda, es el "Guazú_Nambí1" llora a una hembra, que se perdió una noche por los bosques, al sentirla llorar, él también deja escaparse una lágrima. Es su vena, horizontal lamento cristalino. El río "Tacuarí" por sus riberas, va zurciendo la enagua, encadena en puntadas de infinito, el llanto de una india que se adentró a los sarandíes que su cabeza peinan.

Más abajo, humildemente viene estrechando silencios un arroyo. (...)

A orillas del arroyo Conventos creció una villa, que se extendió rápidamente, los años germinaron, se prodigaron cosechas. De pronto ya es un pueblo, el vértigo en los meses se abalanza. Nacen y crecen genuinos pobladores de esta tierra. Hijos del departamento de "Nuestra Señora del Pilar del Cerro Largo". Habría tanto que hablar de todo el tiempo transcurrido hasta ahora, que nos faltan palabras. Mejor imaginemos el comienzo.

El de las calles pueblerinas y embarradas. De pulperías oscuras, ranchos pobres, la plaza reventando en naranjales, sin movimiento alguno, tampoco monumento. Aunque es temprano, no sonaron las campanas de la iglesia anunciando el comienzo de una era ("Sobre el paisaje... El hombre", CdT, 8/6/77).

\footnotetext{
1 Nombres que reciben un Cerro y un arroyo en el departamento de Cerro Largo.
} 
Así describe Tabaré Etcheverry, en su cuaderno de apuntes, la fundación mítica de Melo. Más adelante dará cuenta de su propio nacimiento con la misma carga de imaginería narrativa.

El domingo 28 de octubre de 1945, en el departamento de Cerro Largo, doña Adelaida Tort, esposa de don Antenor Etcheverry, daba a luz a José Francisco Etcheverry Tort, octavo hijo del matrimonio que pasaba sus días en una chacra próxima a la Posta del arroyo Chuy del Tacuarí, que levantaran dos inmigrantes vascos, ambos llamados Juan Etcheverry (tío y sobrino). Años más tarde, el mismo autor en sus canciones no colaboró para que se identificara su nacimiento con la Posta. Aunque muy cercana espacialmente, la familia vivía en una chacra entre los kilómetros 9 y 10 de la ruta 26, en la zona denominada La Pedrera y, según testimonio de su hermana Adelaida, la evocación que se realiza en la canción "Cuando se piensa volver", coincide claramente con la que ella misma guarda de aquel lugar primigenio: "Parcela chica mi amigo/ chica pa vivir tres/ sin embargo cada invierno/ otra boca hacía nacer.// Junto al rancho una pileta/ donde en mormazos la vi/ a mi mama lava y lava/ por eso no me volví." (ETCHEVERRY, 1976). En este paisaje José Francisco "acompañaba" siendo un bebé a su madre, ama de casa, a lavar su ropa en el arroyo Chuy, debajo del puente. Según me confirmara en entrevista su hermana Adelaida, aquel era un lugar despejado y de aguas cristalinas. Recreación de estas imágenes que tal vez obtuvo, años después, del relato de su madre o alguna de sus hermanas, es la canción "Arroyo, ropa y espuma": "De gurí llené mis ojos infantiles y curiosos/ en doblada espalda y cansado paso con rumbo al arroyo/ y de gurí comprendí que el pobre es como el abrojo/ se prende para vivir aunque sea en el arroyo/ romántico para el poeta, para el pobre silencioso" (Ibidem, 1972).

Don Antenor, su padre, era trabajador rural y vendía lo que cosechaba. Hacia 1946 la familia se muda a la capital del departamento, buscando mejores horizontes laborales, según recuerda Adelaida. "El padre de Tabaré repartía pan en un jardinera y le pedía que cantara mientras repartía", me cuenta Ivonne Abella, su segunda esposa. De entre los nueve hermanos, Luis Alberto, Antenor Beltrán, Esther Espínola, Teresita Lucía, Washington María, María Angélica, Adelaida Crisolina y Raquel Marina, estas últimas fueron quienes se relacionaron más estrechamente con él por cuestiones de cercanía en edad. Adelaida confesó en la entrevista que le realizara, que siempre vio a su madre cantando y que ella misma llegó a cantar flamenco de muy buena forma reconociendo así sus raíces españolas.

En cuanto al pequeño Pepe (apodo que utilizan sus familiares y muchas de las personas que lo conocieron personalmente), ya en su época escolar, seguramente seducido por los tablados y el movimiento carnavalesco, integra una murga de niños, Los Cuyanitos. Refiere Guillermo Pellegrino: "Quienes estuvieron cerca de él en esa primera etapa lo recuerdan como un niño silencioso, sensible y muy observador" $(2003$, p. 6), a riesgo de que parezca un lapsus insalvable, debo referir que también lo recuerdan así, mezclando alguna imagen romántica, aún hoy, vecinos que conocieron no al niño, sino al joven Pepe. Luego, esta imagen de solitario e introvertido cambiará mucho con los años y en la noche montevideana que sabrá conocer y frecuentar.

El recuerdo de aquellos primeros días se filtrará también en algunas de sus canciones en claro homenaje a esos orígenes murgueros. Canciones como "Pescadores a la caña" (1972), nos brindan un panorama amplio de la época pues se nombra desde el título un clásico tablado de Melo. También menciona murgas: La Pelotita, La Clásica pichonada, La Cucaracha, Don Bochinche. Luego, costumbres ya desaparecidas como el hecho de comer una porción de sandía por un vintén. Por otro lado, variantes lingüísticas típicas de esa zona geográfica: "biñuelos", en vez de buñuelos. Y, sobre todo, los inevitables "personajes" que todo pueblo reconoce como parte de su identidad: el Oso Lima, Muleque, Jején.

En ese tiempo, según su hermana Adelaida, el poeta y payador Carlos Molina (Melo, 1927 - Montevideo, 1998. Véase Nazabay, 2013) había adoptado a Pepe como hijo. Él y el recitador Rufino Mario García (Canelones, 1925), hicieron varios tablados con "el gurí", el mismo que luego seguiría sus huellas.

\section{Montevideo, cantor guitarrero}

$$
\begin{array}{r}
\text { Allá en medio del campo } \\
\text { conoces hasta los teros } \\
\text { y acá habiendo tanta gente } \\
\text { son toditos forasteros. }
\end{array}
$$

Un período aproximado de tres años separa la llegada definitiva de José Francisco Etcheverry a Montevideo de sus primeros discos, Él es uno de nosotros-Tabaré Etchveverry le canta a José Artigas, editado por RCA (1969) o Tabaré Etcheverry, del sello Macondo (1971). Este período es el menos documentado de su vida, además él mismo se salteó el comentario de tal etapa en su cuaderno.

Hacia 1964 se había casado con Nilza Borba y el nacimiento de su primera hija, al que le dieron el nombre de la madre, en medio de vicisitudes económicas, obliga al novel matrimonio a trasladarse, como ámbito de mayores posibilidades, a la capital; experiencia ambigua que lo hará transitar a su gusto por la noche y las concurridas vinerías de esa época, pero que lo llevará a enunciar 
versos pesimistas como los que encontramos en el tema "Quedate en el norte" del disco La obra bienvenida (RCA, 1973): "Hermano quedate en el norte/ no vengas a la capital/ si buscas una esperanza/ aquí no la has de encontrar.// Hay unas casas tan altas/ que al sol no dejan pasar/ hay que ponerse el barbijo/ para poderlas mirar." De todas formas, esta queja artística no condice mucho con los testimonios de quienes rodeaban a Tabaré. Su hermana Adelaida se encontraba viviendo ya en la capital y le consigue un puesto, según ella bien remunerado, en el bar y restaurante La Vascongada ${ }^{2}$, lo que le permitió dejar de trabajar como repartidor en una pizzería. Tampoco se verifica tal sensación de desamparo en los apuntes de su cuaderno.

En esos primeros años capitalinos Etcheverry frecuenta vinerías y conoce muchos referentes de su época y también a algunos de los que luego serán los nombres más importantes de la canción rioplatense: Mercedes Sosa, Roberto Goyeneche, José Carbajal ("El Sabalero"), Jorge Cafrune, Alfredo Zitarrosa, el dúo del Olimar, Pepe Guerra y Braulio López (cf. FABREGAT y DABEZIES, 1983).

\section{Bache de silencio}

Un gran velo negro se nota en los apuntes de Etcheverry en su cuaderno. "Bache de silencio" lo llama el poeta Washington Benavides (1930-2017), en sus "Definiciones sobre el Canto Popular", precisamente en la revista capitalina Canto Popular (1983, p.9). Es la época en la que se comienza a gestar la dictadura y no son poco importantes las carencias que viven algunos artistas destinados al ostracismo y el silencio. Es la época también en que muchos se deciden por estar en uno u otro bando, no hay puntos medios:

La noche se abría en abanicos cálidos, recibiendo en el seno de las peñas, al cantor. Por sobre el vino, el canto. (...) Se sabía. Se cantaba esa noche, más no había exactitud de hacerlo nuevamente al otro día. Por esa razón, se hilaba con la música y el verso un poncho de silencio. Cubriendo poco a poco, respetuosamente, guitarras, guitarreros (Sin título, en CdT).

Resulta paradójico que en sus apuntes señale algunos compañeros que no llegaron a gozar de popularidad, pues los calló el tiempo o no tuvieron la suerte necesaria. Y es razonable, por otro lado, que él mismo se viera ya dentro de un grupo bastante selecto de cantores populares cuya trascendencia venía en franco ascenso. A pesar de las vicisitudes con los empresarios de la música, Etcheverry

\footnotetext{
2 "Frente a la Plaza de El Entrevero, estaba La Vascongada con sus húngaras y panceta acompañadas por una gran jarra de cerveza. Ese local tenía la forma de un largo corredor que llegaba hasta la calle San José y las mesas se ubicaban pegaditas a la pared" (GRENE, 2010).
}

parecía confiar en su estrella y, por supuesto, tenía razones para hacerlo. Él mismo llegó a inaugurar su propia peña, El mulitero, que duró muy pocos meses. Según su viuda, estaba ubicada en la zona del Cordón, cerca del Palacio Legislativo.

Entre tantos amigos y compañeros de camino que rodearon e impulsaron la breve carrera artística del cantautor hay una persona ineludible, Susana Mayol. Bajo el subtítulo "Los difusores de la época", Tabaré Arapí comenta: "La música popular uruguaya comienza a contar con espacios en emisoras de radios y canales de televisión. Varios periodistas se convierten en difusores de la misma" (2006, p. 18), y cita, entre otros, El fogón de las 11, programa radial emblemático que dirigía Mayol, en el que aquel participó como tantos otros en esa época.

Respecto a esta relación de amistad, extraigo las palabras del poeta Washington Benavides:

En 1966, este Tabaré Etcheverry (...) se traslada a Montevideo, "descubierto" por una conductora de programas de música "folklórica", Susana Mayol, quien cumplió, durante mucho tiempo, una encomiable labor de difusión de la música popular rioplatense, dando cabida a los nuestros, en su programa de Radio Sarandí "El fogón de las Once" de Susana Mayol. (...) Tabaré canta en los centros más publicitados de esos años: Teluria, La Cumparsita, y sobre todo en De Cojinillo, donde Los Olimareños acaudillaban los principales cantores de esos años. La potente voz de Tabaré, con un registro pasmoso de graves, y una natural impostación que le permitía recurrir al falsete o "voz de cabeza", sin quebrantos, nucleó en su torno fanáticos de su canto. Tabaré ya estaba creando sus canciones (BENAVIDES, 1984, p. 31).

De esos tiempos iniciales también debe mencionarse su incipiente inclinación hacia la pintura. Relata Ivonne Abella que se reunía ocasionalmente con pintores en El Portón de San Pedro, en calle Rincón y Ciudadela o en Reconquista y Brecha, otro lugar frecuentado por artistas. Según Abella, doña Nola, conservó siempre las pinturas de su hijo.

\section{7 - Julián Murguía (Martín Ardúa) - Teluria}

Por más que pasen los años No olvide cómo empezó, De aquel que lo aconsejó Que le supo dar la mano De ese que es amigo hermano Cuando flojo se sintió $Y$ acorralado lo vio Él se llegó hasta su rancho Y le abrió un camino ancho Por el cual usté escapó.

1967 es un año de importancia radical en la carrera de cantautor que comienza a gestar José Francisco 
Etcheverry. Gregorio Duarte, músico coterráneo de Tabaré, establece este año como el que marca el inicio de su proyección nacional y, además, agrega un juicio crítico: "se caracterizó por hacer uso -aunque a veces, también abuso- de su extraordinaria voz, desatendiendo la parte instrumental, como asimismo la estructura formal de muchas canciones" (DUARTE, 2010, p.44). En este tiempo logra actuar en los cuatro canales de televisión de Montevideo (4, 5, 10 y 12), filmando, en el primero, un tape con las mellizas Kessler. ${ }^{3}$ Pero es el encuentro con un hombre el que quizá pueda resultar más significativo en la carrera profesional de nuestro protagonista.

En la obra de Etcheverry no puede soslayarse la presencia de Julián Murguía, autor de los textos de varias de sus canciones a quien conoció en Teluria, en 1967. El propio Murguía (quien a veces firmaba con el seudónimo de Martín Ardúa y que además era primo lejano de Tabaré), en un programa homenaje realizado en una emisora de Melo, se encargó de relatar que ese binomio había sido fruto de la casualidad. "Una vez estábamos Zitarrosa, Tabaré y yo tomando vino y conversando en un boliche hasta que en un momento de la noche le reproché a los dos: 'parece mentira que ninguno de ustedes le cante una canción a Artigas...'. Tabaré, así la cosa, tomó una hoja y de inmediato me desafió: 'Escribila vos', me dijo, y fue así que surgió mi primer texto de canción. El día que la tuve pronta y se la mostré (era la letra de la canción "1815"), recuerdo que los dos se 'pelearon' pero la 'manoteó' Tabaré, que luego la incluiría en su primer álbum simple que contenía cuatro canciones dedicadas a Artigas. Para mí, eso sigue siendo lo más lindo o al menos lo más sentido que hicimos con Tabaré" (PELLEGRINO, 2003, p. 7).

No es, por supuesto, menor el encuentro entre Etcheverry y Ardúa, pues los beneficios serán mutuos. Asimismo encarnan un hecho que parece ya tradicional en la canción, la asociación entre un músico-cantor y un escritor. Asociación que no siempre beneficia tanto al escritor como lo hace con el cantor pues suele ser su nombre el que más se recuerde respecto a las letras. En la tradición uruguaya existen grandes ejemplos de esto, Washington Benavides y su sobrino Carlos, o Rubén Lena y Víctor Lima con el dúo Los Olimareños.

Un caso extraño surge al encontrar una semblanza que realiza Zitarrosa para la revista Nueva Viola (y que luego será usada en el contratapa del Volumen 3 de la Antología), en el año 1984 en la que, además de afirmar

\footnotetext{
3 Mellizas alemanas, estrellas infantiles que triunfaron en el Festival de Eurovisión en 1959 y recalaron brevemente en Argentina.
}

algo tan contundente como: "Si exceptuamos al tango y nuestro Julio Sosa, la suya fue la voz mayor del canto popular uruguayo de los últimos treinta años", expresa lo siguiente: "Nunca conversé con él, aunque me hubiera gustado. No tuvimos amigos comunes, salvo un autor, quien sin embargo nunca propició un encuentro; cosas del alma humana. Su gran voz era un milagro de la vida" (ZITARROSA, 1984, p.32). En esta versión de los hechos Zitarrosa niega haber conversado con Etcheverry a pesar del citado testimonio de Murguía que recoge Pellegrino. El músico y compositor Tabaré Arapí aporta un dato más a la posible vinculación o conocimiento de estos dos cantautores, hablando sobre Washington Carrasco propone que: "Es fundador en 1967 del "Centro de la Canción Popular" junto a Daniel Viglietti, Alfredo Zitarrosa, Aníbal Sampayo, Tabaré Etcheverry, Los Olimareños, Víctor Manuel Pedemonte, Ángel Iros" (Arapí, 2006: 45). Es posible que la leyenda negra que recayó sobre Etcheverry por esos años haya provocado el olvido real o forzado por parte de Zitarrosa.

Fuera de estas anécdotas y de las tácitas sugerencias que plantean una interrogante quizá difícil de resolver ya, lo cierto es que la amistad entre Murguía y Etcheverry fue de lo más importante puesto que los llevó a componer un importante número de canciones.

En 1969 se divorcia de Nilza Borba (ya tenían tres hijas: Nilza, Graciela y Raquel) y emprende, además, el camino de la edición. Ese año aparece el disco que incluye la canción a la que se hace referencia en el posible encuentro Etcheverry - Ardúa - Zitarrosa. Un disco simple doble titulado Él es uno de nosotros Tabaré Etcheverry le canta a José Artigas. Contiene dos canciones en cada cara. Según Ivonne Abella, este disco "significó mucho, era su gran ilusión y salió el 23 de setiembre, justo la fecha en que muere Artigas". Es realmente una pieza difícil de hallar pues los coleccionistas o aficionados que lo tienen en su haber lo cuidan con mucho celo. Es además una obra de arte en sí misma pues observamos un cuidado especial desde la carátula, que ostenta la reproducción de una obra del pintor constructrivista Edgardo Ribeiro, titulada Artigas, hasta el interior, donde se guardan a ambos lados los discos bajo la solapas de las tapas. Todas las caras ofrecen información y, además, contiene un suelto que presenta las letras de las cuatro canciones contenidas en el disco: de un lado "1815" y "La Redota" y del otro "Cielo del Protectorado" y "Décimas al Cumba Viejo". Este fonograma lo sitúa en la línea de la canción histórica que da cuenta de hechos y nombres fundacionales del Uruguay. 


\section{1, cantar opinando}

\author{
Quisiera caerme muerto no tengo dónde \\ quisiera para vivir una razón \\ es dura la vida hermano pal que no tiene \\ nada más que dos manos y el corazón.
}

Casado en segundas nupcias con Ivonne Abella, la que será su compañera hasta el fin de sus días, continúa explorando y explotando laboralmente la noche, pero también se acerca a las discográficas, quizá menos por cuenta propia que por la insistencia de algunos amigos. En 1971 graba su primer Long Play en el que incluye la canción "Tabaré" (La elección del nombre charrúa es un homenaje al personaje del poema homónimo de Juan Zorrilla de San Martín), que tras sus presentaciones en vivo le había dado nombre al propio Pepe. El L.P. incluye ocho pistas, en su portada aparece un retrato en acuarela del intérprete, fechado "VII/71", perteneciente al artista tacuaremboense Wilmar López y, en la parte trasera, unas palabras que dan cuenta del color local que ha ido ganando el cancionero rioplatense desde la década del sesenta. En el año 72 se reedita este álbum, ahora con una caricatura de Hermenegildo Sábat y una presentación, en la parte posterior, del poeta y compositor argentino Hamlet Lima Quintana.

Además de la canción mencionada, Etcheverry incluye, en el lado B y junto a "Pueblito Zequeira", un extenso recitado, "Cuzco rabón", que generó polémica en el ambiente desatando tanto elogios como enfados. Ivonne Abella parte del recuerdo que tiene sobre las repercusiones del tema y se instala en un tema que aún hoy afecta a la figura de Tabaré:

Habían dicho que era un disparate, que no era poético, como otros que les encantó. No me acuerdo de otros temas como de "Cuzco rabón". Habla de todo, critica hasta los mismos padres.

Julián Murguía, no sé qué conocido tenía dentro de la Jefatura en aquel momento. Tabaré era muy conocido de Jorge Salerno que murió en la toma de Pando. En aquel momento Julián sacó a Salerno, no sé si Julián tenía alguna influencia con alguien y capaz que salió la versión de que Tabaré era tira o muy amigo de los milicos, capaz que por eso. Empezó en el 71'y duró años.

Tabaré lo adoraba a Julián, creo que era la persona mejor conceptuada que tenía en su vida.

Y con respecto a eso Tabaré sufrió un disparate, porque se hizo toda una madeja que lo dejó muy mal en esa época. Y a raíz de eso fue que Carlos Molina le escribió un poema.

\footnotetext{
4 Evidentemente la canción alude a la localidad de Sequeira en el departamento de Artigas, pero desde el primer disco de Etcheverry su título está escrito con "z", y así se reproduce en las posteriores antologías.
}

El testimonio de su viuda sobre este tema en particular es confuso, quizá producto de una memoria distorsionada por un trauma que aún no se ha resuelto o porque el tiempo ha ido mezclando las cosas de tal forma que hoy es muy difícil diferenciarlas.

Lo cierto es que este rumor llevó a que, en el mismo año de la edición del disco, Tabaré redactara una carta al semanario Marcha expresando su enojo con respecto a las versiones que circulaban y a su vez ratificando una postura que bien puede ser tomada como política. Desde el título de esta carta, intenta inscribirse en una tradición del canto, la opinión como protesta. Dice Hugo García Robles, que el "poeta-cantor se convierte así en testigo perdurable de los sucesos. Máxime si su canto aspira por convicción, a ser no solamente un mero cantar, sino un cantar que opina sobre el acontecer inmediato" (1969, p. 9). A su vez, como queda explícito desde el epígrafe del libro citado, esta postura entronca con la tradición gauchesca rioplatense. José Hernández, pone en boca de su protagonista, Martín Fierro, la afirmación que unirá, según García Robles, a creadores desde Bartolomé Hidalgo hasta Daniel Viglietti: "pero yo canto opinando/ que es mi modo de cantar" (HERNÁNDEZ, 1939, p. 109, citado por GARCÍA ROBLES). El sentido de la estrofa completa de Hernández, puede ser relacionado fácilmente con algunas ideas que son la base de la canción que dio pie a gran parte de la polémica: "Yo he conocido cantores/ que era un gusto el escuchar,/ mas no quieren opinar/ y se divierten cantando;/ pero yo canto opinando/ que es mi modo de cantar" (Ibidem). También podría recordarse como ejemplo una estrofa de Bartolomé Hidalgo que no sería difícil identificar, por lo menos en su idea, en alguna estrofa de "Cuzco rabón": "Lo lindo es que al fin nos grita,/ Y nos ronca con enojo/ Si fuese algún guapo... vaya:/ ¡Pero que nos grite un flojo!"” (HIDALGO, 1986, p. 89). Si bien García Robles no menciona a nuestro protagonista, queda claro que, Etcheverry, decide integrarse él mismo en esta tradición. Reproduzco, entonces, íntegro el texto exhumado del semanario Marcha, 30 de julio de 1971:

\section{Sección: \\ Cartas de los lectores}

\section{CANTAR OPINANDO}

Yo soy un cantor. Un cantor popular de los que llaman "folcloristas", por interpretar canciones orientales sobre ritmos tradicionales. Vivo para el canto y vivo

\footnotetext{
5 Los versos pertenecen al Cielito "Un gaucho de la guardia del monte contesta al manifiesto de Ferando VII. Y saluda al conde de casa Flores con el siguiente cielito, escrito en su idioma". Hidalgo plantea a partir de este cielito las claras "disensiones" entre la corona española doblegada por Napoleón y los criollos que ya no confían en aquella soberanía. En Tabaré puede leerse el mismo conflicto en términos de poder, principalmente político que ordena sin arriesgarse versus el pueblo que padece estas órdenes.
} 
del canto, que es mi vocación y mi profesión. Pero soy también un artista comprometido con su tierra y con su tiempo, y ese compromiso lo llevo a mi canto, porque soy del pueblo y a él me debo.

Hace un par de años, cuando cantaba noche a noche, en la ya desaparecida vinería 'De Cojinillo', junto al Sabalero, Los Olimareños, Eustaquio Sosa y otros valores de la canción popular, alguien echó a correr un rumor sobre mí, el rumor de que yo era un "tira" disfrazado o un informante de la policía. Ni más ni menos. Al principio me reí. Después me indigné pero, aparte de agarrarme a trompadas en un par de oportunidades, mi actitud fue seguir cantando como siempre. Porque, ¿cómo se combate un rumor, señor director? ¿Cómo se demuestra su falsedad? Yo diría que por las acciones que definen al hombre. ¿Y qué acción más definida puede tomar un cantor que 'cantar opinando'?

Yo creía que con mi canto y con la opinión que de mí tienen los que me conocen de cerca, habría sido suficiente, pero me equivoqué. Me he enterado hace poco que ese rumor no sólo no se extinguió hace tiempo sino que trascendió del limitado ambiente de las peñas a círculos mucho más extendidos de lo que yo me hubiera jamás imaginado. Por eso le escribo hoy. Porque veo que ni mi canto ni la defensa que de mí deben haber hecho mis colegas cantores que bien me conocen, han sido suficientes. Y salgo a hacer un desafío, que no es precisamente a payar de contrapunto. Salgo a desafiar (sin preguntar cuántos son...) al autor o los autores del rumor. Que salgan a la luz, que den la cara y la razón de sus dichos.

Tabaré Etcheverry

A pesar de que, según Ivonne Abella, Etcheverry estaba muy dolido y no encontraba otras salidas que justificar con sus acciones o desafiar públicamente a él o los responsables de los rumores, el conflicto no queda solo en esto. Algunos de sus compañeros emprenden, junto a él y por él, el camino de la defensa. A su vez, transcurrido ya cierto tiempo, siguen apareciendo referencias explícitas al suceso o los dichos que se propagaron en torno a su figura. Tal es el caso que observamos en una nota para $E l$ Oriental, sobre álbum Tabaré Etcheverry (1971), donde, luego de una reseña que apunta exclusivamente a lo interpretativo musical el crítico, que no firma la nota, la cierra con las siguientes frases:

Bienvenido entonces Tabaré Etcheverry, ya superado el equívoco que planeó sobre él varios años, y a pesar de algún amago de plagio aquí y allá, de la pretenciosa ambigüedad de su "Cuzco rabón" (trece minutos de improperios cuyo destinatario no logramos adivinar), y -sobre todo- de la disparatada y muy burguesa tesis del divorcio entre forma y contenido (1972, p. 23).
Es un período crítico en el Uruguay y en América Latina, la dictadura está casi por estallar y, producto de esto que se está gestando y es inminente, surgen los recelos y la desconfianza se hace moneda corriente, junto con el miedo. Washington Carrasco, formando parte de esas semblanzas que se le dedicaran en el año 84 en la revista Nueva Viola, expresaba:

Tabaré siempre igual, sencillo, fraternal, atento a todos y a todo, con una palabra que siempre estaba en su boca ¡HERMANO!, con su sonrisa y su abrazo abierto a la amistad (...), aunque no todos los que tuvieron su amistad la merecieron, la envidia y la falsedad estuvieron en su contra, pero eso ni es historia (CARRASCO, 1984, p. 33).

Por su parte, Carlos Molina, reproduce en esta publicación las cuatro estrofas finales de su poema "Pa'andar sin marca" del libro Grillos y terrones (1980, p.51-52). El poema es un alegato a favor del "gurí cantor" venido desde el pueblo a la una ciudad que no siempre concibe hombres de honor, y donde la envidia y la traición son moneda corriente. Luego, en el año 1993, en el número I de la revista $A B C$ De Lo Nuestro, aparece un texto de Carlos Cresci, fechado un año antes, en el cual se retoma el tema como el recuerdo de una herida mal sanada, pero cuyos fundamentos inexistentes convertían los dichos solo en una crecida infamia (cf.: 12). Por su parte, el musicólogo Coriún Aharonián recuerda un hecho concreto y significativo con respecto a esta polémica, planteando ideas sobre las posturas rebeldes y las conservadoras asumidas en las canciones de la época de la dictadura, aclara en una nota al pie: "Alcance con recordar que la pionera Amalia de la Vega aceptó colaborar con la dictadura, que Tabaré Etcheverry cantó para el «Año de la Orientalidad»" (2004, p. 25). A su vez, Tabaré Arapí manifiesta que ese año:

El Ministerio de Cultura contrata a varios artistas aceptados por el Proceso para recorrer el país con sus espectáculos de corte folclórico tradicionalista, donde no se encuentra ningún nombre de los que después conforman el elenco del denominado 'Canto Popular' (Arapí, 2006, p. 38).

Vale aclarar que Arapí cuenta a Tabaré dentro de ese "elenco del Canto Popular". Pero también puede recordarse la arbitrariedad con la que se prohibía o se aceptaba a los artistas en esa época (cf. Fabregat y Dabezies, 1983), ya que, quien hoy era aceptado mañana podía estar prohibido en tal o cual espectáculo y, días más tarde, podía volver a sortear la censura. Puede corroborarse esto con más de una declaración de la época, sirva como ejemplo, además de la referencia citada, este 
fragmento de una nota titulada "¿Quién le teme a los cantores?", para el diario La Democracia:

Una de las características del Uruguay en los últimos años es que hay cosas que no se dicen públicamente pero que todo el mundo sabe. Una de ellas es que los cantores nacionales están sujetos a un régimen incomprensible de prohibiciones y censura previa.

Durante mucho tiempo, en las radioemisoras hubo carteles que advertían sobre la prohibición de pasar discos de Los Olimareños, Alfredo Zitarrosa, Daniel Viglietti, Numa Moraes, Mercedes Sosa, Joan Manuel Serrat, Violeta Parra, etc. Llegó a estar vedada la difusión de textos de Neruda. Paulatinamente la medida fue siendo más flexible respecto a los extranjeros, mientras mantuvo su vigor ante los uruguayos. Sin embargo, nunca se llegó a prohibir la salida al aire de materiales grabados por los cantores que permanecieron (o surgieron) en el país con posterioridad a 1974.

Esa situación de relativa libertad (relativa por la autocensura de muchos), tuvo su contracara en lo que se refiere a las actuaciones en público. Inicialmente no había que pedir permiso a la policía para los recitales a realizarse en salas teatrales, pero sí para los efectuados en estadios cerrados, colegios y lugares por el estilo. Pero ya en aquel momento los cantores debieron conocer las tribulaciones provocadas por un mecanismo que hoy prohíbe a fulano (solista o integrante de un conjunto) y autoriza al resto, y que en la próxima oportunidad lo deja cantar a él y no a los otros. La misma suerte corren las letras de las canciones, que pasan o no el filtro, sin que nunca se sepa porqué (S/f 1981, p. 2).

Existe, además, una última versión sobre la polémica que mantuvo el nombre de Etcheverry en duda. Se trataría, según me lo confiara en entrevista el intérprete y compositor Héctor Numa Moraes, de un rumor que alguien echó a andar con el único objetivo de desprestigiar el nombre de aquel. Y, por último, retomo la mención que me hiciera en una charla informal Washington Benavides, opinando sobre el tema que, en alguna ocasión, se cruzaron en el camino con Tabaré cuando a él lo llevaban los militares para alguna "sacudida" y a este lo traían maltrecho.

Lo cierto es que, si bien Tabaré no estuvo preso, no se salvó de algunas noches de calabazo y tampoco de algunas golpizas, más frecuentes si se encontraba en el interior, según cuenta su viuda. De esto último surgió la tesis que presentaba la enfermedad, que luego lo llevó tempranamente a la muerte, como un posible producto de los maltratos recibidos.

\section{Un 21 de abril}

Se nos van las golondrinas en bandadas

Pues termina el verano y es el tiempo

En que empiezan a quedar solos los nidos

En que empiezan a quedar solos los nidos

Algunos días antes de su cumpleaños, en el mes de octubre, había sufrido un fuerte dolor que lo llevó a internarse por un período considerable. Una de las últimas entrevistas, si no la última, apareció en un suplemento de los sábados del diario El País, en la sección llamada “iquien es quien?” [sic], firmada con las iniciales I. S., bajo el título: "TABARE ETCHEVERRY: Apenas un eco de otras voces". En esta Tabaré reafirma el vínculo con su tierra y las dificultades de la vida como artista. Asimismo sostiene que ese es el camino que él ha elegido y es una forma de compartir con los demás su vida (cf. 1978, p. 4)

El día 21 de abril de 1978 Etcheverry fallece en su casa, a los treinta y dos años, víctima de cáncer. Dejaba una larga nómina de canciones y, junto a ellas, un número más grande aún de seguidores, de gente que creía en su canto y que, en ese día amargo y lluvioso se acercó para despedirse. Las puertas de su casa estuvieron abiertas como él mismo las mantuvo en vida $y$, tras esta postrera confianza, también se suscitaron hechos de lo más disímiles. El recuerdo de Ivonne Abella parte de aquella tapa del primer Long Play reeditado:
Él murió en plena dictadura, en aquella época, además de ser lo que era, la gente, cualquier hecho de esos, lo utilizaba para juntarse, era una manera de pelearla en algo. Entonces vino muchísima gente. Me quedó una sola tapa y sin el disco.
Me acuerdo una especie de fila enorme para pasar la gente a saludar. En un momento entró un policía, vestido de policía, a darle un beso y nadie dijo una palabra. Fue impactante, yo creo que todo el mundo que estaba ahí quedó impactado.
Cuando Tabaré actuaba en La Cumparsita, había gente buena y gente mala, como en todos lados. Y había dos o tres milicos que lo querían mucho. Yo los llegué a conocer después de un tiempo.

Si solo pretendiéramos hacer una lectura fácil de este último acontecimiento esto podría servir para revivir aquella larga controversia que tuvo tan preocupado a Tabaré, de todas formas eso sería un facilismo de los más deplorables. A quién puede ocurrírsele que hasta los cantores más comprometidos no hayan tenido entre aquellos que detentaban el poder, u obedecían a los que detentaban el poder, un número también importante de admiradores. Rescato un testimonio del musicólogo Coriún Aharonián que puede ilustrar al respecto: 
Así como el gobierno nazi utilizaba la Quinta Sinfonía del republicano y revolucionario Beethoven como marco de sus anuncios a la población, los comunicados 4 y 7 de las Fuerzas Armadas son difundidos de la mano de grabaciones de Los Olimareños, el símbolo uruguayo "nacional y popular" por excelencia entre 1966 y 1974, portavoces como Viglietti de la lucha armada por la justicia social. La deseada confusión acerca de la verdadera filiación ideológica del golpe es conseguida sobre todo con la manipulación de este símbolo comunitario. Claro que muy poco después, Los Olimareños van a ser los primeros y únicos músicos populares en merecer un decreto entero de prohibición por parte del poder ejecutivo. Los civiles no estaremos autorizados a escuchar a Los Olimareños, ni siquiera a poseer sus discos. Los soldados rasos y los suboficiales serán descubiertos en sus cuarteles por algún civil de pasada-obligatoria-escuchando, a pesar de todo, a Los Olimareños. Muchos oficiales (y altos oficiales) serán descubiertos después de la dictadura por sus propios hijos poseyendo colecciones completas -a menudo malhabidas- de Los Olimareños o de otros protagonistas de la música popular (AHARONIÁN, 2007, p. 142).

Por último, Carlos Molina estuvo a cargo del discurso en el último adiós a sus restos mortales. A partir de ese momento se han sucedido si no en abundancia al menos sistemáticos homenajes a su figura, además de las letras que se le dedicaron en varias revistas. En el año 1994, Ramón Báez le dedica, en su libro Del mismo palo, los siguientes versos:

\section{A Tabaré Etcheverry \\ Por los rumbos de las coplas musicales de los cerros se despeñó canto arriba rodando contra los vientos. Del Cerro Guazunambí y los valles de su Melo fue recogiendo en cantares los sentires de su pueblo para volcarlos en coplas maduradas en secreto y ritmos germinadores en los rastrojos del tiempo \\ Ya el sol madura las trojes de su corazón inquieto... Y los aires musicales -troperos del sentimiento- lo van arreando y al trote por la rosa de los vientos Ya han florecido sus cantos por otros valles y cerros... Las cañadas y los ríos los entonan en silencio hasta cruzar el olvido y las murallas del tiempo}

¡Cid campeador de la copla, has de cantar hasta muerto!...
En el año 1995, cuando la ciudad de Melo cumplió 200 años, fueron recordadas cuatro figuras relevantes, Dagoberto Vaz Mendoza, Carlos Molina, Amalia de la Vega y él, a la cual asistieron sus hijos, la madre y la esposa. Vale recordar que en Melo hay un busto, hoy un tanto descuidado, en la avenida Tabaré Etcheverry, nomenclatura propuesta por el entonces intendente blanco conservador Villanueva Saravia, frente al estadio municipal "Antonio Eleuterio Ubilla". En vísperas de un nuevo aniversario, el sábado 27 de octubre de 2012 fue homenajeado, a su vez, en el Club de Residentes de Cerro Largo.

\section{Referencias}

\section{Corpus}

Inédito: Cuaderno de apuntes de Tabaré Etcheverry (en el cuerpo de nuestro trabajo CdT).

Entrevista con la Sra. Ivonne Abella, Montevideo, 19 de octubre y 20 de noviembre de 2010.

Entrevista con la Sra. Adelaida Etcheverry. Montevideo, 14 y 15 de febrero de 2011.

Entrevista a Héctor Numa Moraes. Montevideo 16 de julio de 2012.

\section{Libros y revistas}

AHARONIÁN, Coriún. La resistencia y la música uruguaya II. Memoria social y música. En: Brecha, Montevideo, n. 947, p. 24-25. 23 de enero, 2004.

AHARONIÁN, Coriún. Músicas populares del Uruguay. Montevideo: Comisión Sectorial de Educación Permanente/ Universidad de la República, 2007.

ARAPÍ, Tabaré Petronio. Las voces del silencio. Historia del Canto Popular 1973-1984. Montevideo: FONAM, 2006.

BÁEZ, Ramón. Del mismo palo. Montevideo: Ed. de la Banda Oriental, 1994

BENAVIDES, Washington. Canto popular. En: Canto Popular, Montevideo, n. 1, p. 9, agosto 1983.

BENAVIDES, Washington. Tabaré Etcheverry, una voz nuestra. En: Nueva Viola, Montevideo, año 1, n. 2, p. 31, Mayo 1984.

BRAVO, Luis. Voz y palabra. Historia transversal de la poesía uruguaya 1950-1973. Montevideo: Estuario, 2012.

CARRASCO, Washington. Tabaré Etcheverry x9. En: Nueva Viola, Montevideo, año 1, n. 2, p. 34, mayo 1984.

CRESCI, Carlos. Hay un cantor que sigue... En: $a b c$ de lo nuestro, Valgraf, Montevideo, v. I, p. 12, 1993.

CRESCI, Carlos. Hay un cantor que sigue... En: $a b c$ de lo nuestro, Valgraf, Montevideo, v. I, p. 12, 1993.

DOSSE, Francois. El arte de la biografia: entre historia y ficción. México: Universidad Iberoamericana. 2007.

DUARTE, Gregorio. Música popular en Uruguay. Los últimos sesenta años. Melo: S/e, 2010. 
ETCHEVERRY, Tabaré. Cantar opinando. En: Marcha, Montevideo, año XXXIII, n. 1554, 30 de Julio 1971.

FABREGAT, Aquiles; DABEZIES, Antonio. Canto popular uruguayo. Buenos Aires: El Juglar, 1983.

GARCÍA ROBLES, Hugo. El cantar opinando. Montevideo: Alfa, 1969.

GRENE, Luis. 16 de mayo de 2010. Almacenes y bares del viejo Montevideo. Disponible en: <http://www.Ir21.com.uy/ comunidad/410322-almacenes-y-bares-del-viejo-montevideo>. Accedido en: 1 nov. 2017.

HERNÁNDEZ, José. Martín Fierro y La vuelta de Martín Fierro. (Prólogo y notas de Eleuterio F. Tiscornia). Buenos Aires: Losada, 1939.

HIDALGO, Bartolomé. Obra completa. (Edición y prólogo de Antonio Pradeiro). Montevideo: Edición y prólogo de Antonio Pradeiro, 1986. (Colección de Clásicos Uruguayos).

I.S. TABARE ETCHEVERRY: 'Apenas un eco de otras voces'. En: El País, suplemento Sábados Show, sábado 14 de enero de 1978: 4 [I.S.: prablemente se trate de Ignacio Suárez].

MOLINA, Carlos. Grillos y terrones. Montevideo: Corporación Gráfica, 1980.

NAZABAY, Hamid. Canto popular. Historia y Referentes. Montevideo: Ediciones Cruz del Sur, 2013.

PELLEGRINO, Guillermo. El cantor olvidado. En: El País Cultural, Montevideo, n. 718, p. 6-8, 8 ago. 2003.
S/d. "Discos". En: El Oriental, Montevideo, 23 jun. 1972, p. 23.

ZITARROSA, Alfredo. Tabaré Etcheverry x9. En: Nueva Viola, Montevideo, año 1, n. 2, p. 32, mayo 1984.

\section{Discos}

Él es uno de nosotros - Tabaré Etcheverry le canta a José Artigas. (1969) RCA.

Tabaré Etcheverry. (1971), Macondo.

Tabaré Etcheverry interpreta a Tabaré Etcheverry. (1972), Macondo.

La obra bienvenida. (1973), RCA.

Un chasque de amor. (1974), RCA.

Cuando se piensa volver. (1976), Macondo.

Crónica de hombres libres. (1984), Sondor.

Por siempre Tabaré. (1979), Macondo.

Tabaré Etcheverry - Antología, v. 1 al 7 (1981-1994), Sondor.

Lo mejor de Tabaré Etcheverry. (1994), Sondor.

Recebido: 01/12/2017

Aprovado: 24/01/2018

Contato:

Juan Carlos Albarado <jcalbara@gmail.com> 